\title{
On the seductions of psychoanalytic story-telling: Narcissism and the problems of narrative
}

\section{ABSTRACT (200 words max.)}

In this paper I argue for a particular reading of narcissism that challenges the privileging of narrative as a sense-making device, with important consequences for an evaluation of the story paradigm in psychotherapeutic work. I lean on the psychoanalytic mechanisms of nachträglichkeit and trauma to trouble dominant therapeutic logics that support the primacy of the (narcissistically centered) narrative 'I'. Rather than endorse the story of 'me, me, me' that popular readings of narcissism invoke, I explore the possibility that, in psychoanalysis, narcissism's modes destabilise the I, making the narrator constitutionally unreliable, and her accounts of all subject-object distinctions uncertain and constantly shifting.

\section{3-5 KEYWORDS}

\section{Psychoanalysis, narrative, narcissism,}

\section{Julie Walsh}

Anton Chekov, the late nineteenth-century Russian writer who excelled at the short story form, advised that when composing a story, writers should cultivate the habit of cutting-off the beginning and the end. Why? For the simple reason that it is here that we are especially prone to lie. The clinician, as much as the story-teller, may agree that beginnings and endings are particularly vulnerable to falsehoods and fabrications on the grounds that it is at these critical junctures that we strain most to give sense and shape to experience. Invoking the literary wisdom of beginning in medias res, Chekov, then, encourages us to remain alert to the false notes of our own compositions, and perhaps, as a consequence, to retain a degree of scepticism within our reading and writing practices. In this paper, I want to keep in mind Chekov's literary advice and ask what resonance it may have once transposed to the clinical frame.

As far as clinical practice goes, we might readily think of patients who come along, session by session, with their first lines prepared; patients who may, in time, come to articulate their propensity to script themselves into speech. We might also think of patients who make clear that they are, one way or another, profoundly wedded to the particular version of the story that they are compelled to recount; 
patients for whom the once upon a time signals the opening of a narrative that, to begin with at least, must remain utterly faithful to the received and established coordinates of plot and character. When stories are worn too tightly - taken as gospel, so to speak - then the teller risks becoming a mouthpiece for a story that, in truth, she is yet to make her own.

When Sigmund Freud comments on the unexpected similarity between the case histories he writes and the short stories composed by imaginative writers, he does so in defence of his science:

\footnotetext{
[...] it still strikes me myself as strange that the case histories I write should read like short stories and that, as one might say, they lack the serious stamp of science. I must console myself with the reflection that the nature of the subject is evidently responsible for this, rather than any preference of my own. (Freud 1893: 160)
}

If the form of the case-history were to reflect a preference on the part of the writer, its scientific objectivity, Freud implies, would be compromised. The reason, then, that Freud's case histories resemble short stories is because the psychoanalytic symptom can only be made intelligible when listened to in the context of the "story of the patient's sufferings" - hence the Doctor's account of the case will necessarily reflect the shape of his patient's story (1893: 161). That much is straightforward enough. Perhaps though, it is deceptively straightforward. Without dismissing Freud's explanation - or is it an apologia? - for the form his clinical writing takes, there is another, distinctly Freudian line of thought to open up here, namely that psychoanalysis does not really deal in stories at all, at least not in any idea of a story that adheres to a narrative model of smooth chronological progression through beginning-middle-and-end. For a story to begin we need to set the scene, to understand where the patient-protagonist has come from, perhaps give a bit of family history, or an insight into her motivations for being on the couch. And in order to end, we have to have a sense that, not only have we travelled, but have also arrived somewhere, and that we are, as a result, in a position to given an account of the journey. This is the form that conventional clinical narration invariably takes. But there is certainly something missing in this, something about this story that does not quite ring true. 
Frequently, collections of psychotherapeutic case-studies, especially those intended to cross-over between clinical and mainstream publics, deploy the terminology of the tale in their title (a prime example being Irvin Yalom's Love's executioner and other tales of psychotherapy, 1991). ${ }^{1}$ Central to this idea of the tale is the seduction of story-telling to which I refer in this paper's title. As is known to anyone who has delivered stories to children at bedtime, the demand is placed on the teller to repeat the story without difference; it is the familiarity of the tale that assures the child's pleasure economy is not irrevocably disrupted. This is not to say that there is no place for punctuating moments of arrest, surprise or horror within the story's unfolding, but, much like the resolution achieved in a piece of music by the final sounding of an established cadence, when the last page is turned the audience will have been reassured (their psychic equilibrium restored) by the known conventions of form. The principle of narrative consolation is thus central to the logic of the clinical tale. Indeed, the psychoanalytic Ur-tale Fort-Da! is often taken to epitomise this very logic. ${ }^{2}$ However, as will be my suggestion, the tale also keeps us connected to Chekov's warning about the lie. "Tell-tale-tit! / your tongue will split / and all the little birdies / will have a little bit," so goes the familiar playground chant wherein the teller of tall tales is denounced as a tell-tale. If, as readers, we are now accustomed to "trusting the tale," can we necessarily say the same of the teller (Kreiswirth 1992)? Or, perhaps more pertinently from a clinical perspective, what conception of the speaking subject is proffered when psychotherapeutic work is directed towards the goal of telling a coherent narrative?

Writing prior to the embedding of the so-called narrative turn in the AngloAmerican Humanities, the literary critic Lionel Trilling noted in 1973 that "a chief part of the inauthenticity of narration would seem to be its assumption that life is susceptible of comprehension and thus of management" (135). In tune with Chekov's counsel, Trilling's account of the "inauthenticity of narration" will be worth bearing in mind: specifically, I propose to consider how the assumption that narration is

\footnotetext{
${ }^{1}$ Diverse examples stand alongside Yalom's, which vary in the way they blend case-history with memoir, fiction and other genre conventions, include: The fifty-minute hour: A collection of true psychoanalytic tales (Lindner 1999); Couch tales: Short stories (Kennedy 2009); The stolen girl and other stories: seven psychoanalytical tales (Touton-Victor 2011); Tales from the therapy room: Shrinkwrapped (Lapworth 2011); Let's keep talking: Lacanian tales of love, sex, and other catastrophes (Baldwin 2016) - the list goes on.

${ }^{2}$ See, for example, Terry Eagleton's account in which Fort-Da! stands the "shortest story we can imagine" on the grounds that it provides a template for (object) loss and (object) recovery from which even the most "complex narratives" then derive (1996: 160).
} 
commensurate with comprehension and life management has been uncritically extended in recent decades. Whilst we know ideas of narrative coherence have a prominent (and legitimate) place in particular psychotherapeutic modalities, I shall focus on what I regard to be the more problematic area of cultural reception. ${ }^{3}$ Specifically, I want to demonstrate how certain prominent sociological styles have framed therapy as a narrative tool for extending the managerial capacities of what Dennis Wrong famously diagnosed back in 1961 as sociology's “oversocialized conception of man." If, as I contend, the emancipatory potential of narration - or of narrative re-description - is given credence by a cultural zeitgeist in which projects of self-fashioning, self-actualisation, and self-determination all hold sway, then we are invited to think carefully about the term narcissism. When understood in the crude $m e, m e$, me sense of popular readings, narcissism would seem a fitting term to apply to a culture in which social actors use therapy to re-write the star part in their their own stories. ${ }^{5}$ Indeed, from the perspective of 2017 where narcissism has featured heavily in mainstream discourse as the go-to label for both individual and cultural presentations of grandiose, vain, shallow, self-obsessed behaviours, the me, me, me narcissist is a difficult one to ignore. However, to limit our appreciation of narcissism to what we might call this trumped-up version would give a severely jaundiced view of the matter. Narcissism, especially when read for its psychoanalytic complexities, proves a remarkably rich heuristic to work with (as has been the goal of several recent works to demonstrate, e.g. DeArmitt 2014; Lunbeck 2014; Walsh 2015). It is my intention here to demonstrate how a particular reading of narcissism challenges the operation of narrative as a sense-making device, which, in turn, should encourage us to reflect on the general value of the story paradigm for psychotherapeutic work.

\footnotetext{
${ }^{3}$ Unfortunately, it falls beyond the scope of this article to map the lines of influence between the sizeable fields of narrative psychology and narrative medicine, and the development of psychotherapeutic models. That said, we should recognise the part played by the rise of trauma studies in forging the link between narrative reconstruction as a therapeutic enterprise, and narrative as a general human and political value. It makes sense to cite Judith Lewis Herman's seminal work here as a prominent example of such a link: Herman states that rather than being defeated by that which seems to defy narrative, the combined work of the therapist and patient enables a therapeutic recovery whereby "in the telling, the trauma story becomes a testimony" (1992: 181).

${ }^{4}$ Wrong formulated that such a conception could only fail to acknowledge the importance of "biography, of the motivational depths and complexities of the human heart, and of the somatic, animal roots of our emotional lives" - all components of social life that psychoanalytic, feminist, queer, and affect oriented analyses have kept more firmly in the picture in recent decades (Wrong 1977: 54).

${ }^{5} \mathrm{I}$ have argued elsewhere that, not without reason, a certain lineage of cultural criticism makes synonymous the terms "therapy culture" and "narcissistic culture" (Walsh 2015: 82-114).
} 
To move through this terrain, I propose the following development. First, rather than begin in the metapsychological landscape, I want to think about how the story of therapy itself has been narrated, and how this story is invariably framed with reference to the concept of narcissism. Most obviously, there are the cultural commentaries from the 1970s to acknowledge wherein narcissistic pathologies are understood as a symptom of cultural malaise (Christopher Lasch 1979; Richard Sennett 1974; Tom Wolf 1976; Jim Hougan 1975). Allowing for considerable variation on the theme, the logic here runs that narcissism rises in accord with the decline of cultural authority and the impoverishment of public space - twin factors that feed into the "veritable discursive explosion" of all matters therapeutic. ${ }^{6}$ The "triumph of the therapeutic," as Philip Rieff (1973 [1966]) first coined the phrase, has proven an enduring motif beyond the cultural declinism of the 1970s, segueing more recently with critical assessments of the emotional state(s) of cultural life, and the status of emotions in cultural discourse. We will notice that within this field of discourse there is an understanding of therapeutic logic that supports the primacy of the narrative $I$. Second, I shall outline the most salient aspects of a psychoanalytic account of subject-formation that disrupt such a vision. Here we shall see how any conventional sense of narrative movement from beginning through middle and on to end is thoroughly undermined by the concept of Nachträglichkeit, a model of temporality and causality that was necessitated by the Freudian theory of trauma. By radically upsetting time's arrow, we will observe how psychoanalysis insists on the difficulty of telling a story straight. Next, attending to both the scenic and structural components of narcissism, I shall advance a double claim to show how, psychoanalytically understood, narcissism is both that which appears to establish the foundation for the narrative subject, and that which insists on undermining anything that could be called a narrative identity. Our discussion here will remain connected to the development of Freud's account of trauma via the theory of the drives. When, by the end of the paper, we are in a position to consider the characteristics of a so-called narcissistic story, rather than find an account of $m e$, me, me that popular readings of narcissism would invoke, we may find narrative modes that destabilise the I, making the narrator constitutionally unreliable, and her accounts of all subject-object distinctions uncertain and constantly shifting.

\footnotetext{
${ }^{6}$ The coinage, of course, is Michel Foucault's regarding sex talk (1988: 17).
} 


\section{Narrative selfhood in therapeutic culture}

The guiding premise of this paper is that the psychoanalytic project reminds us that as soon as we put an account of ourselves into story form, we risk speaking beyond our means; certainly, we risk speaking out of sync with the radical implications of a psychoanalytic theory of the subject. However, the talking cure also insists that we must, of course, endeavour to speak! And it is true that we cannot speak without recourse to stories of some form or another. "Deprive children of stories," warns the moral philosopher Alasdair MacIntyre, "and you leave them unscripted, anxious stutterers in their actions as in their words" (2007 [1981]: 216).

I want in this section to problematize a particular trend in contemporary thought whereby the achievement of a self-driven narrative -a story in which the narrative I convenes the project of self-actualisation - is taken to be the principal goal of therapeutic work. To explore this line of development it will be helpful to be reminded of what Denise Riley has referred to as "that usual antithesis [...] between language as speaking us, and our status as freely choosing users of language" (2005: 3). Inclined to reject the either/or in favour of the both/and, a psychoanalytic approach would have it that as we endeavour to master language, we will be forever mastered by it; as we narrate, so too we will be narrated. But this insistence on the limitations of our empowered self-narration does not necessarily connect with culturally prevalent accounts of the therapeutic project. Whilst it would be bizarre (if not disingenuous) to suggest that psychotherapy does not work in the service of aiding the subject's capacity to narrate his- or herself, the point of qualification that I am keen to make is that when the vision of an empowered (or even omnipotent) narrator becomes synonymous with a broad brush cultural understanding of therapy, it is then increasingly difficult to imagine ways in which psychotherapeutic work might resist the directives of the prevailing social order.

Anthony Giddens's highly influential and deeply contested sociological framing of the therapeutic project can serve as our inroad to this discussion. Giddens' work in this area revolves around his concept of "the reflexive project of the self," which is defined as "the process whereby self-identity is constituted by the reflexive ordering of self-narratives" (1991: 244). The late-modern self, like the late-modern institution, is concerned with strategies of life planning through which the negotiation of risk and the colonisation of the future can be routinely narrativised. The project of 
therapy for Giddens is, in short, a project oriented towards control, with "self determination" as its core goal. It is interesting to note that the principal way in which Giddens differs from the prior generation of sociologists writing on emergent conceptions of selfhood concerns the critical tenor of his evaluation: for Christopher Lasch (1979) and Richard Sennett (1974), for example, with whom Giddens is in active dialogue, the rise of therapeutic practices and mores was coincident with the decline of traditional forms of authority: famously, the name ascribed to this state of affairs was narcissism. ${ }^{7}$ Writing in the $1970 \mathrm{~s}$, these cultural commentators diagnosed as narcissistic a culture lacking in stable moral coordinates around which one could authorise one's biography. Giddens, however, is confident that by "late modernity" the prevalence of therapeutic discourses should not be read symptomatically as evidence of "narcissistic withdrawal" on a cultural scale, but, rather, that "therapy should be understood and evaluated essentially as a methodology of life planning" (1991: 180). Although we can admit that Giddens's appreciation of therapy as a tool in the integrative project of life planning is not out of sync with certain psychotherapeutic presentations, the point to draw out here is that once the self is conceived as a planning project - or a project of self-design/self-fashioning - the question of authorship becomes again critical: a model of therapy oriented to control and self-determination, it strikes me, presupposes a simplistic version of the I who narrates.

If, for Giddens in the 1990s, the note of emphasis was on therapy as an expression of a generalised reflexivity, it has been necessary for subsequent commentators to consider more critically how therapeutic projects interact with the narratives of selfhood formed by particular socio-political orders. Much of this work has occurred as a critique of neoliberal practices of self-governance. ${ }^{8}$ According to the entrepreneurial principles of neoliberalism, the self is formulated as a mode of human capital driven to invest itself - via particular routes of self-improvement - in the pursuit and acquisition of happiness, freedom, and personal fulfilment. The degree to which therapeutic logics can be anything other than complicit with neoliberal agendas remains an open debate. As the critic Eva Illouz observes, through an emphasis on

\footnotetext{
${ }^{7}$ This line of analysis can be encapsulated by Philip Rieff's effective coinage "where theology was [...], there therapy had to be" (cited in Bourne et al. 1987: 74).

${ }^{8}$ See Steven Groarke's Managed lives: Psychoanalysis, inner security and the social order (2014) for a detailed case study of the place of Giddens's sociology within neoliberal frameworks of selfgovernance.
} 
what she dubs "diseases of the will," "therapeutic discourse offers endless possibilities for coherently narrativizing the life story" (2008: 196). The logic runs that once therapy is regarded as attending to pathologies of individual will - i.e. diseases of one's own self-making - then any movement in the direction of cure will inevitably entail a re-making, a refashioning or re-narrativising of one's wilful identity. lllouz, like many, is deeply critical of the tendency in contemporary therapeutic logics to make self-authorship the redemptive feature of the work; she explains, "therapeutic narratives can be faulted for making too much sense of one's life, of binding too tightly the present, the past, and the future in a seamless narrative of psychic wounding and self-change" (2008: 196). We shall return below to this idea of being bound too tightly to futural objects and ideals in a story of linear, temporal progression. For now, we can summarise that when experiences of distress and suffering are chalked-up as failures of individual choice and life management, the structural and materialist causes of mental ill health are thoroughly side-lined. This ideological focus on the individual - where the individual is to be the agent responsible for the production and consumption of a satisfactory story about her own well-being - has been a staple feature of critical accounts that resist the totalising effects of a so-called therapy culture.

Clearly, then, the quest for a seamless narrative is not the exclusive preserve of a therapeutic world-view, rather it is a salient feature of many disciplinary logics that ally sense-making and story-telling as the tools with which human beings navigate their worlds. Within such disciplinary logics it is possible to identify, as Nikolas Rose does in his important critique of the "psy. disciplines", a "cloying humanism" that overestimates the degree to which the human agent is able to actively negotiate the narratives available to him or her (1998: 178). Rose explains that in the social constructionist accounts of selfhood found in the contemporary psychological literature (and we should add sociological literature here too),

the human being is understood as that agent which constructs itself as a self through giving its life the coherence of a narrative. Evidently, "the self," simply by virtue of being capable of narrating "himself or herself" in a variety of ways, is implicitly re-invoked as an inherently unified outside to these communications. (Rose 1998: 177) 
To refer back to terms used earlier, such a self would be a freely choosing languageuser (rather than someone who is spoken by language). Rose's sceptical evocation of a speaking subject whose very capacity to make narrative sense of her life is what gives that life an inherently unified shape, brings us more firmly in line with psychoanalytic critique.

As a discourse of the divided subject, psychoanalysis thoroughly disrupts the image of a coherent narrator who is in command of her use of language from a position of one remove; in fact, the spectacle of an "inherently unified outside" (Rose 1998: 177) if read through the Lacanian schema of the mirror stage (of which more below), evokes the first of the subject's fateful seductions with the narcissistic image. We shall see later that this narcissistic seduction of the self by the self is by no means straight-forward, and, importantly, the case can be made that Rose's criticism of the "psy disciplines," or Illouz's of "therapeutic discourse," need not wholly apply to psychoanalysis; that somehow (and there are compelling arguments to be made in this vein), psychoanalysis stands to the side of the dominant therapeutic logics we may be concerned to critique. However, I am not convinced that such an exemption should be made too quickly, especially on the question of the discipline's narrativising impulse.

In his Narrative knowing and the human sciences, academic and practising therapist Donald Polkinghorne (1988) leans on the work of literary critics Peter Brooks and Steven Marcus to make the case that the psychoanalytic model of psychic health corresponds to a coherent narrative. Polkinghorne quotes Marcus to summarise this position:

Human life is, ideally, a connected and coherent story, with all the details in explanatory place, and with everything (or close to everything as is practically possible) accounted for, in its proper causal or other sequence. And inversely illness amounts at least in part to suffering from an incoherent story or an inadequate narrative account of oneself. (Marcus quoted in Polkinghorne 1988: 179)

For Polkinghorne, or anyone else for that matter wishing to establish psychoanalysis's primary orientation to narrative, there is an abundance of evidence to draw from. ${ }^{9}$

\footnotetext{
${ }^{9}$ See, for example, Rudnytsky and Charon's edited volume of 2008, Psychoanalysis and narrative medicine.
} 
Françoise Meltzer for example argues that "the very process of psychoanalysis entails the construction of a linear, cogent narrative" because the "goal of analysis is to have the patient reconstruct a 'better,' more cohesive story as the analysis progresses." (Meltzer 1995: 155). Whilst Meltzer places the idea of a "better" story in the obligatory scare quotes - presumably to problematize the notion of judgement - the real difficulty here is that the principle of narrative-making leaves un-problematized the particular qualities that it presupposes, namely linearity, cogency, and coherence. Notwithstanding the variance of narrative models at work across this body of literature, it is my contention that such qualities are retained by those for whom, to quote a further powerful exponent of this position, "it makes sense to think of psychoanalysis in narrational terms" (Schafer 1980: 30).

That the construction of a story inevitably entails a degree of "narrative smoothing" (Spence 1986), is articulated in the Freudian concept of the dream work's "secondary revision" whereby, in accordance with "considerations of intelligibility" the dreamer will in effect begin to tidy-up the absurdities of her dream material prior even to her waking-up (Freud 1900: 666). Here is Freud in Totem and taboo where the principle of secondary revision receives further attention:

There is an intellectual function in us which demands unity, connection and intelligibility from any material, whether of perception or thought, that comes within its grasp; and if, as a result of special circumstances, it is unable to establish a true connection, it does not hesitate to fabricate a false one. (Freud 1913: 95)

This "intellectual function" can stand as the sense-making work of story-telling, as I have begun to sketch it out. Remembering Trilling's thought above that "the inauthenticity of narration would seem to be its assumption that life is susceptible of comprehension and thus of management" (1973: 135), we might want to observe here in Freud's description, how our inevitable striving for coherence is wont to lead to the fabrication of false connections. The elaborations and rationalisations that accompany "narrative smoothing" are, even within the context of the dream work, already acts of artful dissemblance. Which leads us to ask what kind of account the psychoanalytic subject may be able to give of herself that does not avail of the narrative mode? In powerful distinction to the line of thought encapsulated above (Meltzer, Schafer, 
Polkinghorne, etc.), Judith Butler, in her (2005) text, raises the following challenge for psychoanalytic storytelling:

But what if the narrative reconstruction of a life cannot be the goal of psychoanalysis, and that the reason for this has to do with the very formation of the subject? If the other is always there, from the start, in place of where the ego will be, then a life is constituted through a fundamental interruption, is even interrupted prior to the possibility of any continuity. (Butler 2005: 52)

Rather than stressing the salvific function of narrative, Butler offers psychoanalysis as a way to attend to the subject's irreducibility to narrative: By taking seriously the principle of a radical split at the heart of the subject, she postulates "a fundamental interruption" that sets in motion the subject's inevitable narrative failings, thus making the narrative I a necessary fiction. We are now a far cry from the "cloying humanism" of the narrative self that has mastered her story of self-fashioning. If we stand by Butler's position then we would have to go further than Chekov and suggest that it is not only in the beginnings and the endings that the story-teller is liable to lie, but that the narrative mode itself is, at bottom, deceptive. In which case, we are tasked with following Butler's lead and exploring psychoanalysis's theory of subjectformation to develop an account of the ways in which psychoanalysis might challenge the seductions of a straight story.

\section{Twice upon a time: Traumatising time's arrow}

In order to comprehend the non-linear models of temporality and causality that psychoanalysis foregrounds - models articulated under the sign of Nachträglichkeit, après coup, afterwardsness -, it is necessary to consider the status of trauma and its link to sexuality. Recognising that Freud's theorisation of trauma altered considerably over the period of his writing (in fact, it is not too strong to say that the developments of his "trauma theory" provide a parallel and contracted account of the history of Freud's psychoanalysis writ large), it is nonetheless possible to identify how the basic tenets of his account signal psychoanalysis's resistance to the seduction of linear tales.

In his Project for a scientific psychology (1895), Freud details an element from an early case to exemplify the Nachträglich production of traumatic sexuality. It is worth rehearsing briefly here: Freud explains that at the time of treatment, his patient, 
"Emma," was suffering from "a compulsion of not being able to go into a shop alone" (1895: 353). Emma offers a memory from her early adolescence as a way to make sense of her prohibitive compulsion: she remembers going into a shop alone at the age of twelve whereon she encountered two shop assistants who were "laughing together [...] at her clothes." Their laughter prompted Emma to run out of the shop "in some kind of affect of fright, and, Freud adds, she also recalled that one of the shopassistants had "pleased her sexually" (1895: 353). Emma's recollection of this scene leaves Freud with more questions than answers - why, he asks, would the memory of this minor humiliation retain the power to make his patient avoid shops nearly fifteen years later, now that she was a fully-grown woman who could be confident of her sense of dress? Moreover, Emma's anxiety was specifically linked to going into a shop alone, a fact, Freud suggests, that does not tally with the potential to be laughed at on account of what one is wearing. But then the treatment yields a second memory; second, that is, within the order of Emma's narration of herself to her analyst, but chronologically prior within the terms of Emma's biography. Freud tells us that:

On two occasions when she was a child of eight she had gone into a small shop to buy some sweets, and the shopkeeper had grabbed at her genitals through her clothes. In spite of the first experience she had gone there a second time; after the second time she stopped away. She now reproached herself for having gone there the second time, as though she had wanted in that way to provoke the assault. (1895: 354)

Freud describes how the first scene (Emma's memory of the two shop assistants at age twelve) is linked to the second scene (Emma's memory of the shopkeeper at age eight) via the association of the shop assistants" laughter to the "grin" of the shopkeeper who had grabbed her. It is important to stress that the encounter with the shopkeeper is presumed to have aroused no sexual excitement in Emma as she experienced it, and therefore it cannot strictly be described as "traumatic" (where trauma involves a somatic reaction). However, between the ages of eight and twelve, the intervening event of puberty re-inscribes Emma's memory of her formative encounter with the shopkeeper with an affect that it did not originally possess: "The memory aroused what it was certainly not able to at the time, a sexual release, which was transformed into anxiety. With this anxiety, she was afraid that the shop- 
assistants might repeat the assault, and she ran away" (1895: 354). The "sexual release" of the second scene was transformed into anxiety precisely because it occurred in association with the earlier memory: in other words, finding one of the shop assistants "sexually pleasing" constituted an encounter with her own active desire that, because associated in her mind with the memory of the shopkeeper's assault (and her wilful returning to the shop a second time), overwhelmed Emma and compelled her to flee from the situation. As Laplanche and Pontalis make clear in their explanation of trauma's Nachträglich production, the quality of "trauma" is only conferred on the earlier memory "after the fact" (Nachträglich) - "it is only as a memory that the first scene becomes pathogenic by deferred action, in so far as it sparks off an influx of internal excitation" (1988: 467).

I recount this case here to stress that the work of reconstructing a narrative to make sense of Emma's symptom challenges the order of cause and effect through which the patient is accustomed to speak: the sexual trauma cannot be conceived as a singular event, isolable at a discrete point in the historical past. Rather "at least two events," or two scenes separated by a period of time, are required for the traumatic "memory" of the first to be created by the occurrence of the second (Laplanche and Pontalis 1986: 9). That a secondary repetition is necessary to constitute the trauma of the so-called originary scene provides a frame to read some of Freud's most enigmatic formulations such as the idea that "hysterics suffer mainly from reminiscences" (Freud 1893: 7), or that "the patient will begin his treatment with a repetition" (Freud 1914a: 150). Which means that the logic of before and after is shunted off course, and the story-telling convention of once upon a time becomes heavily ironized. All of which is to say that when a subject narrates her story under the sign of Nachträglichkeit, she is moved beyond the commonplace temporal wisdom that acknowledges the influence of the past on the future, and instead repositioned vis a vis a past that will remain subject to the retroactive influence of that which follows it, and, indeed, that which may still be to come.

We shall see now how this discussion bears on our reading of narcissism. By undermining a straight temporality, the logic of Nachträglichkeit cannot but pose a radical challenge to the subject of narration. How are we to understand the founding of the I as the beginning of a narrative, once its status as an historical act of settlement has been so thoroughly disrupted? And if, in accordance with a psychoanalytic understanding of the unconscious, time is fundamentally shattered (Green 2002), what 
modes of clinical story-telling are possible? It is necessary, then, to look further into the founding scene of self-identification that psychoanalysis poses.

\section{Narcissism: For and against narrative}

The exemplary scene of narcissistic seduction to which we can now turn is Jacques Lacan's account of the mirror stage (2006 [1949]). Here, we are asked to imagine the moment at which a baby meets herself for the first time, and does so via the presence of an image. Though the mirror stage is synonymous with the Imaginary realm, we must also see that by providing an apparatus through which the subject will present her body to herself (and to the external world), this staged performance in the Imaginary is simultaneously the gateway to the Symbolic - (Lacan in effect makes the baby a little philosopher when he has her experience herself as subject and object in front of the mirror). It is this encounter with the specular image that catalyses the subject's on-going narrative quest. On sight of her reflection the subject makes the narcissistic declaration "there I am" before journeying into the future via a series of iterative pronouncements. In other words, from the inaugural moment that she jubilantly assumes the image before her, the subject remains at arm's length from that which she takes herself to be. Critically, this distance safeguards the onward momentum of her desire and simultaneously structures the temporal form of her identity. In psychoanalytic parlance, the term lack is used to designate this paradox whereby a subject's self-assurance rests upon not having full possession of herself; being obliged to move forward in a quest of self-becoming to an imaginary moment of identity (a moment which is, of necessity, deferred), the subject is temporalized. In these terms, lack stands for the promise of the future, which draws the subject out into an essentially narrative form.

If, however, this is the full story of the subject's narcissistic beginnings, we must ask wherein lies the psychoanalytic resistance to the narrative version of selfhood that I have been alluding to throughout this paper. For narcissism to disrupt rather than consolidate a narrative account of identity, something else must be going on. A further possibility, then, residing within the narcissistic scene is that the narrative set in motion by the subject's desire to meet the image in front of her (to be identical with her image) is at the same time that which covers over the incoherent and distinctly unnarrativisable quality of the drive. In other words, narcissism-asnarrative is the cover story for something altogether less seductive. We can get a 
stronger sense of this account of narcissism by remembering why it is, within the terms of Lacan's story, that the baby makes her identification with the image she meets in the mirror in the first place. In short, she does so precisely because the attractive wholeness of her reflection - with its delineated contours and surface planes - offers relief to the uncoordinated reality of her actual, embodied experience [Lacan evokes the violence of Hieronymus Bosch's artwork to convey the "aggressive disintegration" of a fragmented and "fragilized" body ungoverned by the $I$ function (2006: 78).].

The function of what Lacan calls méconnaissance (or misrecognition) "characterises the ego in all the defensive structures" - and what is always being defended against through misrecognition is the pressure of the drives (2006: 80). Although by no means straightforward, we can say of drive theory that it describes the coming together of organic and bodily processes with psychical structure, and in particular frames our understanding of the sexual. The drives are also at the heart of an understanding of narcissism insofar as Freud's landmark (1914) paper "On narcissism: An introduction" struggles to define its object. Indeed, the major interest of Freud's paper resides in the strategic slippages between narcissism as belonging to an originary ego, and narcissism as defining an originary state of non-distinction between infant and mother, self and world (i.e. an oceanic feeling of oneness). ${ }^{10}$ Freud's elusive conclusion, which arrives tellingly enough at the mid-point of his essay, is that "a unity comparable to the ego cannot exist in the individual from the start" (1914b: 77). Crucially, this permits us to speak of narcissism without necessarily speaking of the ego (and its defences).

A narcissism of self-shattering in other words, of dissolved or undefined or inexistent borders between self and other - what would this look like, or, more appropriately, how would it make itself felt? Freud gives us a clue in his account of the sexual, specifically how the "polymorphously perverse disposition" of the infant demonstrates the unbounded nature of the drives before they are directed according to the "civilising" forces of "shame, disgust and morality" (1905: 191). Freud of course plays his own hand in directing the drives through the drama of the Oedipus Complex (with its "correctly" gendered resolutions), and yet his work has given enough

\footnotetext{
${ }^{10}$ That Freud vacillates between narcissism as the definition of the ego as an object, and as the priority of an objectless state accounts for the principal difficulty of the paper (cf. Laplanche and Pontalis 1988: 255-7).
} 
suggestive weight to pre-oedipal and perverse sexualities to allow for critical reevaluation. For instance, when he writes that the sexual drive and the sexual object are "merely soldered together" he disturbs the root of his own cultural narrative (1905: 147). Whatever prominence he gives to the unfolding drama of Oedipus, he cannot efface the original contingency of this soldering: the moment at which the drives are given an object, and sexuality is given over to an approved orientation.

To shift the metaphor once more, this contingent moment of soldering the sexual drives to a sexual object replicates the knot of the narcissistic scene referred to above where the ego instantiated in imaginary identification with itself is at the same time a dereliction of a prior (if illusionary) oneness in which the dilemmas of identity and lack do not yet have a hold. If psychoanalysis is uniquely placed to take the drives seriously, as I suggest it is, then it must be underpinned by a theory of narcissism that disrupts as well as consolidates the narrative subject. Which is to say, a narcissism of drives, of attachments to part objects, and of a dynamic metabolisation of the world rather than a narcissism of the ego. There are significant narratological consequences to this point of emphasis, which concern both time and character. As any reader of queer theory today already knows, the normative organisation of the drives and sanctioning of particular egoic pleasures necessarily positions the subject within established, well-storied timelines and in relation to idealised figures (the parent, for example). Inherent to a narcissism of drives, however, is the possibility of counternarrative and indeed of anti-narrative. To take just three prominent queer critiques: Lee Edelman, in his book No future (2004), writes of sexuality and the drives as antinarrative, and (after Joan Copjec) of narcissism as constantly interrupting all of its own representations. Leo Bersani, in his development of an aesthetic of narcissism, builds on the premise that "the human subject is originally shattered into sexuality," and finds in Freud's 1914 paper a model for narcissistic self-shattering that translates beyond the field of metapsychology into experimental fields of sociability (1990: 36). Judith Halberstam offers qualified support for this strand of queer discourse, noting that sex gets cleaned up when made about "self-fashioning rather than self-shattering" (2011: 149). As well as presenting a queer challenge to normative practices, reproductive ethics and modes of intersubjectivity, where the only accepted relations are those between already idealised human subjects, these authors deliberately return to narcissism and the metapsychological entanglements found therein to question the link between cultural practice and narrative sense. 
In conclusion, it remains for me to bring together two strands of my argument: narcissism, and the Nachträglich character of trauma. My suggestion is that once narcissism is conceptually de-soldered from the object of the ego, it can be taken, more productively, to represent the trauma of subject-formation. ${ }^{11}$

To read narcissism as disruptive of narrative is to remain in tune with the temporal dislocations of trauma noted above (e.g. Nachträglichkeit, afterwardsness). If trauma is a way of de-narrativising the subject, it is unsurprising that psychotherapeutic theory and practice has focused often on the subject's renarrativisation; however, as I have suggested over the course of this piece, there are several problems with such an approach. Patricia Clough's introduction of the concept of "enactive witnessing" to trauma discourse is helpful here: working against a narrative model, Clough argues for a clinical mode of treating trauma that focusses not on the deconstruction and reconstruction of narratives, but on the transmission of bodily affect. Looking specifically at material from psychoanalytic sessions, she notes that a clinical stance of enactive witnessing "is not itself curative on narrative terms" (Clough 2009: 156), thus challenging the position of much trauma theory. Although Clough's intervention is targeted specifically at the theorisation and treatment of trauma, it also represents (with general psychoanalytic applicability) an embodied theory of language. She writes:

in enactive witnessing, language is allowed to drop down or fall back to the medium depth of the body, producing a deeper decomposition of meaning than the deconstruction and reconstruction of narrative. Language becomes less about content and more about the accompanying rhythms of affect - the punctuated, pulsing beats in sound - moaning and groaning, or in the calming or agitating bodily gesture rocking, rubbing, twisting, twitching and quivering. (2009: 156)

To stress the rhythm of language, rather than its content, is to arouse the pre-linguistic registers of the "fragilized" body in Lacan's schema - at that point prior to which the exemplary baby seduces herself with the correct and proper object of her ongoing

\footnotetext{
${ }^{11}$ In speaking of subject-formation under the aegis of 'trauma', I am implicitly aligning my position with recent moves in critical theory away from the trauma-as-exceptionality thesis (e.g. Berlant, 2011).
} 
fascination (i.e. herself!). Clough's choice of language also makes plain how the rhythms of affect - transmitted through speech and bodily gesture - animate the body in ways that recall Freud's many descriptions of the child's polymorphous capacity for sexual feeling. In this light, and considering our proposed decoupling of narcissism from the object of the ego, the more urgent analytic task becomes not one of placing language in the service of narrative, but rather of perceiving how language is already lodged in medias res, inside the body.

\section{References}

Baldwin, Yael. 2016. Let's keep talking: Lacanian tales of love, sex, and other catastrophes. London: Karnac.

Berlant, Lauren. 2011. Cruel Optimism. London, Duke University Press.

Bersani, Leo. 1990. The culture of redemption. London: Harvard University Press.

Bourne, Bill, Udi Eichler \& David Herman (eds). 1987. Voices: Psychoanalysis. Nottingham: Spokesman Press.

Butler, Judith. 2005. Giving an account of oneself. New York: Fordham University Press.

Clough, Patricia T. 2009. Reflections on sessions early in an analysis: Trauma, affect and "enactive witnessing." Women \& performance: a journal of feminist theory 19(2). $149-159$.

DeArmitt, Pleshette. 2014. The right to narcissism: A case for an im-possible selflove. New York: Fordham University Press.

Eagleton, Terry. 1996. Literary theory: An introduction. Oxford: Blackwell Publishers.

Edelman, Lee. 2004. No future: Queer theory and the death drive. Durham/London: Duke University Press.

Foucault, Michel. 1988 [1976]. The history of sexuality, Volume 1. The will to knowledge. London: Penguin Books.

Freud, Sigmund. 1893. Fräulein Elisabeth von R. Case histories from studies on hysteria. In James Strachey (ed.), The standard edition of the complete psychological 
works of Sigmund Freud, Volume II (1893-1895): Studies on Hysteria, 135-181. London: The Hogarth Press.

Freud, Sigmund. 1895. Project for a scientific psychology. In James Strachey (ed.), The standard edition of the complete psychological works of Sigmund Freud, Volume I (1886-1899): Pre-psycho-analytic publications and unpublished drafts, 281-391. London: The Hogarth Press.

Freud, Sigmund. 1900. On Dreams. In James Strachey (ed.), The standard edition of the complete psychological works of Sigmund Freud, Volume V (1900-1901): The Interpretation of Dreams (Second Part) 630-686. London: The Hogarth Press.

Freud, Sigmund. 1905. Three essays on the theory of sexuality. In James Strachey (ed.), The standard edition of the complete psychological works of Sigmund Freud, Volume VII (1901-1905): A case of hysteria, three essays on sexuality and other works, 123-246. London: The Hogarth Press.

Freud, Sigmund. 1913. Totem and taboo. In James Strachey (ed.), The standard edition of the complete psychological works of Sigmund Freud, Volume XIII (19131914): Totem and taboo and other Works, vii-162. London: The Hogarth Press.

Freud, Sigmund. 1914a. Remembering, repeating and working-through (further recommendations on the technique of psycho-analysis II). In James Strachey (ed.), The standard edition of the complete psychological works of Sigmund Freud, Volume XII (1911-1913): The case of Schreber, papers on technique and other works, 145156. London: The Hogarth Press.

Freud, Sigmund. 1914b. On narcissism: An introduction. In James Strachey (ed.), The standard edition of the complete psychological works of Sigmund Freud, Volume XIV (1914-1916): On the history of the psycho-analytic movement, papers on metapsychology and other works, 67-102. London: The Hogarth Press.

Giddens, Anthony. 1991. Modernity and self-identity: Self and society in the late modern age. Cambridge: Polity Press.

Green, André. 2002. Time in psychoanalysis: Some contradictory aspects. London: Free Association Books.

Groarke, Steven. 2014. Managed lives: Psychoanalysis, inner security and the social order. London, Routledge.

Halberstam, Judith. 2011. The queer art of failure. Durham \& London: Duke University Press. 
Herman, Judith L. 1992. Trauma and recovery: The aftermath of violence - From domestic abuse to political terror. New York: Basic Books.

Hougan, Jim. 1975. Decadence: Radical nostalgia, narcissism, and decline in the seventies. New York: William Morrow.

Illouz, Eva. 2008. Saving the modern soul: Therapy, emotions, and the culture of self help. London: University of California Press.

Kennedy, Roger. 2009. Couch tales: Short stories. London: Karnac Books.

Kreiswirth, Marty. 1992. Trusting the tale: The narrativist turn in the human sciences. New Literary History 23(3). 629-657.

Lacan, Jacques. 2006 [1949]. Mirror stage as formative of the $I$ function. In: Jacques Formatted: French (France) Lacan. Écrits, 75-81. London: W. W. Norton \& Company.

Laplanche, Jean. \& Jean B. Pontalis. 1986 [1964]. Fantasy and the origins of sexuality. In Victor Burgin, James Donald \& Cora Kaplan (eds.). Formations of fantasy. London: Methuen and Co. Ltd. 5-34.

Laplanche, Jean \& Jean .B. Pontalis. 1988 [1973]. The language of psycho-analysis. London: Karnac Books.

Lapworth, Phil. 2011. Tales from the therapy room: Shrink-Wrapped. London: Sage.

Lasch, Christopher. 1991 [1979]. The culture of narcissism: American life in an age of diminishing expectations. London: W. W. Norton \& Company.

Lindner, Robert. 2007 [1982]. The fifty minute hour: A collection of true psychoanalytic tales. New York: Other Press.

Lunbeck, Elizabeth. 2014. The Americanization of narcissism. Cambridge, Mass.: Harvard University Press.

MacIntyre, Alasdair. 2007 [1981]. After virtue: A study in moral theory, 3rd edn. Norfolk: Duckworth.

Meltzer, Françoise. 1995 [1990]. Unconscious. In Frank Lentricchia \& Thomas Mclaughlin (eds.). Critical terms for literary study, 2nd edn, 147-162. Chicago: The University of Chicago Press.

Polkinghorne, Donald. E. 1988. Narrative knowing and the human sciences. New York: State University of New York Press. 
Rieff, Philip. 1973 [1966]. The triumph of the therapeutic: Uses of faith after Freud. Middlesex: Penguin Books.

Riley, Denise. 2005. Impersonal passion: Language as affect. Durham \& London: Duke University Press.

Rose, Nikolas. 1998. Inventing our selves: Psychology, power and personhood. Cambridge: Cambridge University Press

Rudnytsky, Peter L. \& Rita Charon (eds.). 2008. Psychoanalysis and narrative medicine. New York: Suny Press.

Schafer, Roy. 1980. Narration in the psychoanalytic dialogue. Critical Inquiry 7(1). 29-53.

Sennett, Richard. 1993 [1974]. The fall of public man. London: Faber \& Faber.

Spence, Donald P. 1986. Narrative smoothing and clinical wisdom. In Theodore R. Sarbin (ed.), Narrative psychology: The storied nature of human conduct. New York: Praeger. 211-232.

Touton-Victor, P. 2011. The stolen girl and other stories: Seven psychoanalytical tales. London: Karnac Books.

Trilling, Lionel. 1973. Sincerity and authenticity. Cambridge: Harvard University Press.

Walsh, Julie. 2015. Narcissism and its discontents. Basingstoke: Palgrave Macmillan.

Wolf, Tom. 1976. The "me" decade and the third great awakening. New York Magazine, 23 August. 26-40.

Wrong, Dennis. 1961. The oversocialized conception of man in modern sociology. American Sociological Review 26. 183-193.

Wrong, Dennis. 1977. Skeptical sociology. London: Heinemann Educational Books Ltd.

Yalom, Irivin. 1991. Love's executioner and other tales of psychotherapy. London: Penguin Books. 